\title{
Avaliação da nested PCR em comparação aos testes sorológicos IDGA e ELISA para o diagnóstico da anemia infecciosa equina
}

\author{
[Evaluation of nested PCR compared with AGID and ELISA serological tests for \\ equine infectious anemia diagnosis] \\ E.M. Santos, P.M.C. Motta, M.B. Heinemann, R.C. Leite, J.K.P. Reis \\ Departamento de Medicina Veterinária Preventiva \\ Escola de Veterinária - Universidade Federal de Minas Gerais - UFMG \\ 30 123-970 - Belo Horizonte, MG
}

\section{RESUMO}

Comparou-se a técnica nested PCR (nPCR) com os testes sorológicos IDGA e ELISA para o diagnóstico da anemia infecciosa equina. Amostras do DNA provenientes das células mononucleares do sangue periférico foram submetidas à amplificação do gene gag pela nPCR, que apresentou valores de sensibilidade e especificidade relativas de $90 \%$ e 52,9\%, respectivamente, em relação à IDGA, e valores de $85,7 \%$ e $49 \%$, respectivamente, em relação ao ELISA. Considerando-se os fatores referentes às limitações de cada técnica, pode ser sugerido o uso da nPCR como teste de diagnóstico complementar para AIE em amostras brasileiras.

Palavras-chave: diagnóstico, AIE, nPCR, IDGA, ELISA

\begin{abstract}
The nested polymerase chain reaction (nPCR) technique was compared to AGID and ELISA serological tests for the diagnosis of Equine Infectious Anemia. DNA samples from the peripheral blood mononuclear cells were subjected to the amplification of the gag gene by $n P C R$, which showed relative sensibility and specificity values of $90.0 \%$ and $52.9 \%$ respectively, compared to the AGID and values of $85.7 \%$ and $49.0 \%$, respectively, as compared to ELISA. Considering the factors concerning the limitations of each technique, the use of nPCR can be suggested as a complementary diagnostic test for EIA in Brazilian samples.
\end{abstract}

Keywords: diagnosis, EIA, nPCR, AGID, ELISA

\section{INTRODUÇÃO}

A anemia infecciosa equina (AIE), enfermidade que acomete equinos, muares e asininos, é causada pelo vírus da anemia infecciosa equina (EIAV), que é um Lentivirus da família Retroviridae (Van Regenmortel et al., 2000). A AIE não tem tratamento nem vacina eficaz, portanto o seu controle é feito por meio do diagnóstico laboratorial, com identificação, isolamento e eutanásia ou segregação dos animais soropositivos (Issel e Coggins, 1979), o que torna necessário o desenvolvimento de técnicas de diagnóstico capazes de identificação precisa e precoce da doença.

Recebido em 17 de março de 2011

Aceito em 21 de março de 2011

E-mail: elmaira27@yahoo.com.br
Embora a imunodifusão em gel de ágar (IDGA) seja ainda estabelecida pela Organização Mundial de Saúde Animal (OIE) como teste oficial para o diagnóstico da AIE, atualmente existem várias metodologias para o diagnóstico da enfermidade. Apesar de ser usada em larga escala, a IDGA apresenta algumas limitações, dentre elas a incapacidade de detectar anticorpos específicos nos estágios iniciais da infecção. A interpretação dos resultados, muitas vezes, é subjetiva e dependente da experiência técnica do laboratorista, o que gera resultados não quantitativos e não permite a automatização do teste. Além desses fatores, os resultados são demorados e não existe padronização entre os diferentes kits de IDGA utilizados, 
comprometendo as medidas de controle e a erradicação das doenças (Reis, 1997; Trono et al., 2001; Cappelli et al., 2011).

Frequentes resultados falso-negativos obtidos pelo teste IDGA, com utilização da proteína p26 como antígeno, são comprovados por meio do ELISA indireto com a glicoproteína recombinante gp90 - correspondente à glicoproteína da superfície externa do EIAV (Reis, 1997). Estes testes permitem detectar a maioria dos cavalos infectados, pois são direcionados contra a gp90, os primeiros e os maiores títulos de anticorpos detectados no sangue de animais infectados. Portanto, o uso da rgp90 contribui para o aumento da sensibilidade do ELISA e pode servir como uma alternativa para o diagnóstico da AIE (Reis, 1997; Martins, 2004).

Os testes mais utilizados para o diagnóstico da AIE são a IDGA e o ELISA, em vários formatos, e, embora sejam considerados boas ferramentas, alguns fatores podem contribuir para resultados conflitantes que necessitam de confirmação utilizando-se outras técnicas mais sensíveis e específicas (Trono et al., 2001; Alvarez et al., 2007; Cappelli et al., 2011). Técnicas como a reação em cadeia da polimerase (Polimerase Chain Reaction - PCR) têm sido desenvolvidas, avaliadas e utilizadas como diagnóstico complementar ou confirmatório para AIE assim como para outras retroviroses (Trono et al., 2001; More et al., 2008; Cappelli et al., 2011). Estudos apontam a PCR como o método eficiente para a detecção do DNA proviral do EIAV, identificando equídeos em estágio subclínico, animais recentemente infectados em processo de montagem de resposta imune, e potros com anticorpos colostrais anti-EIAV, que interferem nos testes sorológicos (Toma, 1980; McConnell et al., 1983; Issel e Cook, 1993).

De acordo com a importância do diagnóstico para o controle da doença, e devido às limitações dos testes atualmente empregados para diagnóstico da AIE, este estudo tem o objetivo de comparar as técnicas sorológicas IDGA e ELISA e a nested PCR, amplificando fragmento do gene gag do EIAV de amostras brasileiras do DNA proveniente das células mononucleares do sangue periférico (PBMC).

\section{MATERIAL E MÉTODOS}

Cento e onze amostras do sangue foram obtidas da veia jugular de equídeos, provenientes de frigoríficos localizados em Araguari e Itaobim, MG, Brasil, após antissepsia com álcool iodado e coletadas em tubos do tipo VACUETTE® (Greiner Bio-One Brasil, Americana - SP, Brasil). Amostras dos soros foram separadas por centrifugação a $300 \mathrm{X}$ g por 10 minutos, e as amostras das células mononucleares do sangue periférico (PBMC) foram obtidas do sangue com anticoagulante sendo usado o gradiente de FicollPaque e estocadas a $-20^{\circ} \mathrm{C}$ até a extração do DNA. Amostras dos soros foram testadas para AIE utilizando-se o ELISA rgp90 segundo Reis (1997), e a imunodifusão em gel de ágar de acordo com Nakajima e Ushimi (1971). Amostras de PBMC foram submetidas à extração do DNA genômico utilizando-se fenolclorofórmio-álcool isoamílico, proteinase $\mathrm{K}$ e precipitação com etanol conforme protocolo descrito por Sambrook et al. (1989). As concentrações do DNA foram estimadas por espectrofotometria em comprimento de onda de 260nm.

Para verificar a qualidade das amostras de DNA genômico após os procedimentos de extração, foi realizada a amplificação do fragmento do gene da $\beta$-actina, constitutivo do genoma dos equídeos, garantindo que todas as amostras tivessem acessibilidade à nPCR gag. $\mathrm{O}$ gene $\beta$ actina foi amplificado segundo protocolo descrito por Oaks et al. (1998) com uso dos iniciadores 5', CGACATCCGTAAGGACCTGT 3' (senso) e 5' GTGGACAATGAGGCCAGAAT 3' (antissenso) (primer 3_www_results.cgi v 0.4), gerando um fragmento com 191 pares de bases (pb).

Os oligonucleotídeos iniciadores utilizados para a reação nested PCR foram correspondentes à sequência gag que codifica as proteínas do capsídio do EIAV Wyo. Para amplificação do gene gag, foi utilizado protocolo descrito por Oaks et al. (1998) com uso dos iniciadores internos 854 (5' GGCTGGAAACAGAAATTTTA 3') e 1262 (5' TAGGTTTTCCAATCATCACT 3'), e com os iniciadores externos 636 (5' CCATTGCTGGAAGATGTAAC 3') e 1399 (5' TGCGTTCTGAATAGTCAGTG 3'), gerando um fragmento com 408pb. Os produtos amplificados foram observados sob luz UV após 
corrida eletroforética em gel de agarose $1 \%$ corado com brometo de etídio. Fragmentos amplificados na nPCR gag foram purificados e submetidos ao sequenciamento para confirmação dos resultados.

O DNA extraído de células da linhagem Derme Equina (ED) infectadas com EIAV e o DNA proveniente de células ED não infectadas foram utilizados como controles positivo e negativo da nPCR, respectivamente.

A análise estatística dos resultados foi realizada por meio do teste Kappa, utilizando-se o programa Win Episcope 2.0, que estabelece o índice de concordância entre as técnicas. A concordância é classificada e denominada de acordo com Landis e Koch (1977): valores do índice Kappa $<0$ = nenhuma concordância; valores entre $0-0.19=$ baixa concordância; valores entre $0.20-0.39$ = regular concordância; valores entre $0.40-0.59=$ moderada concordância; valores entre $0.60-0.79=$ substancial concordância; valores entre 0.80 1.00 = alta concordância.

\section{RESULTADOS}

De acordo com o índice Kappa de 0,872 obtido a partir da comparação entre os resultados gerados na IDGA e no ELISA com as 111 amostras testadas (Tab. 1), pode-se considerar que as técnicas sorológicas apresentaram alta concordância (Landis e Koch, 1977) e valores de sensibilidade e especificidade diagnóstica relativas de $96,6 \%$ e 90,2\%, respectivamente. Dentre as amostras de soros testadas no ELISA, 63 tiveram resultados positivos e 48 negativos, e na IDGA 60 resultados positivos e 51 negativos.

Tabela 1. Resultados obtidos com o uso das técnicas ELISA e IDGA para teste de amostras de soros de equídeos com o respectivo índice Kappa

\begin{tabular}{cccc} 
& & \multicolumn{2}{c}{ IDGA } \\
\cline { 3 - 4 } & & Pos & Neg \\
\hline \multirow{2}{*}{ ELISA } & Pos & 58 & 5 \\
& Neg & 2 & 46 \\
& & \multicolumn{2}{c}{ KAPPA $=0,872$}
\end{tabular}

Total= 111 amostras
Na Tab. 2, são apresentados os resultados obtidos da comparação entre a IDGA e a nPCR. O índice Kappa de 0.441 obtido estabelece moderada concordância entre as técnicas (Landis e Koch, 1977), e valores de sensibilidade e especificidade diagnóstica relativas de $90 \%$ e 52,9\%, respectivamente. Dentre as 111 amostras testadas com nPCR gag foram obtidos 78 resultados positivos e 33 negativos, e na IDGA 60 resultados positivos e 51 resultados negativos.

Tabela 2. Resultados obtidos com o uso das técnicas IDGA e nPCR gag para teste de amostras com o respectivo índice Kappa

\begin{tabular}{cccc}
\hline & & \multicolumn{2}{c}{ IDGA } \\
\cline { 3 - 4 } & & Pos & Neg \\
\hline $\begin{array}{c}\text { nPCR gag } \\
\text { PBMC }\end{array}$ & Pos & 54 & 24 \\
& Neg & 6 & 27 \\
& KAPPA $=0.441$ &
\end{tabular}

Total= 111 amostras.

Os resultados obtidos da comparação entre o ELISA e a nPCR são apresentados na Tab. 3. O índice Kappa de 0.371 estabelece regular concordância entre as técnicas (Landis e Koch, 1977), e valores de sensibilidade e especificidade diagnóstica relativas de $85,7 \%$ e $49 \%$, respectivamente. Foram obtidos com o uso da nPCR gag 78 resultados positivos e 33 negativos, e com o ELISA 63 resultados positivos e 48 negativos.

Tabela 3. Resultados obtidos com o uso das técnicas ELISA e nPCR gag para teste de amostras com o respectivo índice Kappa

\begin{tabular}{cccc}
\hline & & \multicolumn{2}{c}{ ELISA } \\
\cline { 3 - 4 } & & Pos & Neg \\
\hline nPCR gag & Pos & 54 & 24 \\
PBMC & Neg & 9 & 24 \\
& KAPPA $=0.371$ & \\
\hline
\end{tabular}

Total $=111$ amostras

Todas as amostras do DNA provenientes de PBMCs submetidas à amplificação com o uso da nPCR gag no presente estudo (Fig. 1) foram previamente amplificadas na PCR $\beta$-actina. Para confirmar a especificidade analítica dos produtos 
amplificados na nPCR gag, foram realizados sequenciamentos das amostras em teste e do controle positivo. A análise do fragmento de 408pb demonstrou identidade nucleotídica com gene gag do EIAV (dados não mostrados).

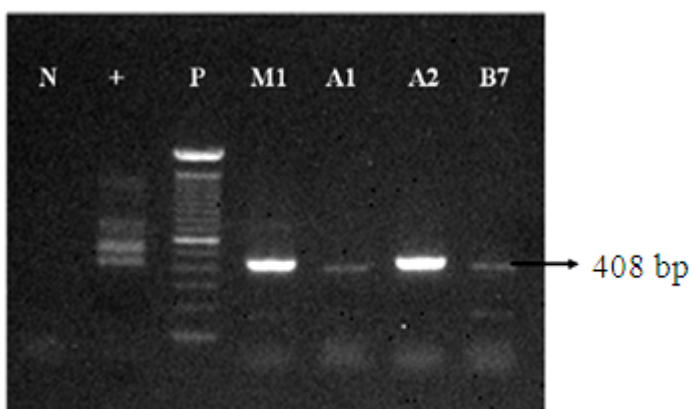

Figura 1. Gel de agarose 1\% com produtos amplificados na nPCR gag. $\mathrm{N}$ : controle negativo; +: controle positivo; M1, A1, A2, B7: amostras do DNA de PBMCs amplificadas; P: marcador de tamanho molecular (100pb - Invitrogen).

\section{DISCUSSÃO}

Os resultados permitem afirmar que ocorreu alta concordância entre as técnicas sorológicas analisadas, apesar da existência de relatos na literatura que apontam o ELISA como mais sensível do que a IDGA, por ser capaz de detectar amostras positivas mais precocemente (Sugiura et al., 1986; Reis et al., 1994; Martins, 2004).

Os índices Kappa gerados a partir das análises dos resultados obtidos com as técnicas sorológicas e a nPCR gag determinaram regular e moderada concordância entre os testes, principalmente devido ao grande número de resultados positivos na nPCR e negativos na sorologia. Resultados similares foram apresentados por Nagarajan et al. (2001), ao utilizarem nPCR gag em comparação à IDGA, sugerindo maior sensibilidade da nPCR. Nos trabalhos de Langemeier et al. (1996) e Ferraz (1998), a PCR foi avaliada com resultados favoráveis, sendo capaz de detectar sequências do genoma viral três a quatro dias pós-infecção. Embora não tenha sido determinado o estágio da doença em que se encontravam os animais no momento da coleta das amostras, pode-se sugerir que os resultados positivos na nPCR gag e negativos na sorologia sejam provenientes de animais em estágios iniciais da AIE, quando ainda não foi estabelecida resposta imune específica. Além desses fatores, deve-se considerar que a resposta clínica em equídeos pode ser controlada por vários mecanismos ainda desconhecidos, baseados nas características virais ou do hospedeiro (Cook et al., 1998). A existência de variantes do EIAV na natureza, com potencial variação patogênica, pode desencadear respostas imunológicas distintas entre os animais e talvez indetectáveis pelos métodos sorológicos indiretos. Para esses métodos sorológicos, geralmente são produzidos e utilizados os antígenos baseados na sequência da amostra selvagem do EIAV, o que pode prejudicar os resultados quando amostras sorológicas de campo são testadas, devido à concentrada presença dos variantes virais circulantes em campo (Leroux et al., 2001; Howe et al., 2002; Sponseller et al., 2007; Cappelli et al., 2011).

No trabalho desenvolvido por Newman et al. (1991), foi registrada maior sensibilidade da PCR em relação à sorologia, principalmente em casos de animais no período de janela imunológica, ou quando existem níveis transientes de anticorpos em associação ao estágio latente com restrita replicação viral. Nessas circunstâncias, os testes de diagnóstico sorológicos podem gerar resultados falsonegativos (Issel e Cook, 1993; Langemeier et al., 1996; Trono et al., 2001).

Desde que os equídeos infectados com EIAV permaneçam portadores por toda a vida e o estágio de infecção inaparente seja mantido, animais sorologicamente falso-negativos podem servir como reservatórios de infecção para os animais não infectados por prolongados períodos de tempo (Issel e Coggins, 1979; Hammond et al., 1997). Portanto, a nPCR poderia ser adotada como diagnóstico confirmatório ou adicional à sorologia, contribuindo para as medidas de controle e erradicação da AIE (Trono et al., 2001; Alvarez et al., 2007; More et al., 2008; Cappelli et al., 2011).

No presente estudo, as amplificações na PCR $\beta$ actina garantiram a qualidade e a acessibilidade das amostras nas reações nPCR. A ausência de contaminantes nos controles negativos e os resultados dos sequenciamentos confirmaram a especificidade analítica dos produtos amplificados. A nPCR gag avaliada no trabalho pode ser utilizada como técnica complementar 
aos testes sorológicos no diagnóstico da AIE para amostras brasileiras, e estudos da variabilidade genética do EIAV no Brasil permitirão a escolha de novos iniciadores e sequências com possíveis aplicações no desenvolvimento de plataformas de diagnóstico para a doença.

\section{REFERÊNCIAS BIBLIOGRÁFICAS}

ALVAREZ, I.; GUTIERREZ, G.; VISSANI, A. et al. Standardization and validation of an agar gel immunodiffusion test for the diagnosis of equine infectious anemia using a recombinant p26 antigen. Vet. Microbiol., v.121, p.344-351, 2007.

CAPPELLI, K.; CAPOMACCIO, S.; COOK, F.R. et al. Molecular detection, epidemiology and genetic characterization of novel european fields isolates of equine infectious anemia virus. J. Clin. Microbiol., v.49, p.27-33, 2011.

COOK, R.F.; LEROUX, C.; COOK, S.J. et al. Development and characterization of an in vivo pathogenic molecular clone of equine infectious anemia virus. J.Virol. v.72, p.1383-1393, 1998.

FERRAZ, I.B.F. Vírus da anemia infecciosa equina: amplificação por PCR do DNA proviral da gp90, comparação com o teste de ELISA e IDGA e variabilidade genética de amostras brasileiras. 1998. 153f. Tese (Doutorado em Ciência Animal) - Escola de Veterinária, Universidade Federal de Minas Gerais, Belo Horizonte, MG.

HAMMOND, S.A.; COOK, S.J.; LICHTENSTEIN, D.L. et al. Maturation of the cellular and humoral immune responses to persistent infection in horses by equine infectious anemia virus is a complex and lengthy process. $J$. Virol., v.71, p.3840-3852, 1997.

HOWE, L.; LEROUX, C.; ISSEL, C. J. et al. Equine infectious anemia virus envelope evolution in vivo during persistent infection progressively increases resistance to in vitro serum antibody neutralization as a dominant phenotype. J. Virol., v.76, p.10588-10597, 2002.

ISSEL, C.J.; COGGINS, L. Equine infectious anemia: current knowledge. J. Am. Vet. Med. Assoc., v.174, p.727-733, 1979.
ISSEL, C. J.; COOK, R. F. A review of techniques for the serologic diagnosis of equine infectious anemia. J. Vet. Diagn. Invest., v.5, p.137-141, 1993.

LANDIS, J.R.; KOCH, G.G. The measurement of observer agreement for categorical data. Biometrics, v.33, p.159-174, 1977.

LANGEMEIER, J.L.; COOK, S.J.; COOK, R.F. et al. Detection of equine infectious anemia viral rna in plasma samples from recently infected and long-term inapparent carrier animals by PCR. $J$. Clin. Microbiol., v.34, p.1481-1487, 1996.

LEROUX, C.; CRAIGO, J.K.; ISSEL, C. J. et al. Equine infectious anemia virus genomic evolution in progressor and nonprogressor ponies. J. Virol., v.75, p.4570-4583, 2001.

MARTINS, M.F. Comparação entre os testes IDGA (p26) e ELISA indireto (rgp90) no diagnóstico da anemia infecciosa equina. 2004. 59f. Dissertação (Mestrado em Medicina Veterinária) - Escola de Veterinária, Universidade Federal de Minas Gerais, Belo Horizonte.

McCONNELL, S.; KATADA, M.; DARNTON, S. M. Occult equine infectious anemia in an immunosuppressed serologically negative mare. Equine Pract., v.5, p.32-39, 1983.

MORE, S.J.; AZNAR, I.; BAILEY, D.C. et al. An outbreak of equine infectious anaemia in Ireland during 2006: Investigation methodology, initial source of infection, diagnosis and clinical presentation, modes of transmission and spread in the Meath cluster. Equine Vet. J., v.40, p.706708, 2008.

NAGARAJAN, M.M.; SIMARD, C. Detection of horses infected naturally with equine infectious anemia virus by nested polymerase chain reaction. J. Virol. Methods, v.94, p.97-109, 2001.

NAKAJIMA, H.; USHIMI, C. Immunodiffusion studies of purified equine infectious anemia virus. Infect. Immun., v.3, p.373-377, 1971.

NEWMAN, M.J.; ISSEL, C.J.; TRUAX, R.E. et al. Transient suppression of equine immune responses by equine infectious anemia virus (EIAV). Virology, v.184, p.55-66, 1991. 
OAKS, J.L.; McGUIRE, T.C.; ULIBARRI, C. et al. Equine infectious anemia virus is found in tissue macrophages during subclinical infection. J. Virol., v. 72, p. 7263-7269, 1998.

REIS, J. K.; MELO, L. M.; REZENDE, M. R. et al. Use of an ELISA test in the eradication of an equine infectious anaemia focus. Trop. Anim. Health Prod., v.26, p.65-68, 1994.

REIS, J.K.P. Produção de antígenos recombinantes gp90 e p26 do vírus da anemia infecciosa equina para uso em imunodiagnóstico. 1997. 184f. Tese (Doutorado em Ciência Animal) - Escola de Veterinária, Universidade Federal de Minas Gerais, Belo Horizonte.

SAMBROOK, J.; FRITSCH, E.F.; MANIATIS, T. Molecular cloning: a laboratory manual. 2.ed. [s.n.]: Cold Spring Harbor Laboratory, 1989.

SPONSELLER, B.A.; SPARKS, W.O.; WANNEMUEHLER, I. et al. Immune selection of equine infectious anemia virus env variants during the long-term inapparent stage of disease. Virology, v.363, p.156-165, 2007.
SUGIURA, $\quad$ T.; $\quad$ MATSUMURA, $\quad$ T.; FUKUNAGA, Y. Diagnosis of equine infectious anemia by enzyme-linked immunosorbent assay with viral antigen purified by affinity chromatografy. Bull Equine Res. Inst., v.23, p.42-48, 1986.

TOMA, B. Persistent negative serologic reaction in a mare infected with equine infectious anemia virus. Recl. Med. Vet., v.156, p.55-63, 1980.

TRONO, K.G.; PEREZ-FILGUEIRA, D.M.; DUFFY, S. et al. Seroprevalence of bovine leukemia virus in dairy cattle in Argentina: comparison of sensitivity and specificity of different detection methods. Vet. Microbiol., v.83, p.235-248, 2001.

VAN REGENMORTEL, M.H.; MAYO, M.A.; FAUQUET, C.M. et al. Virus nomenclature: consensus versus chaos. Arch. Virol., v.145, p.2227-2232, 2000. 